anemone, larkspur, violet, willowherb, scarlet tropæolum, red rhododendron, bilberry, flowering currant, scabious, wild thyme, potato, forget-me-not.

The colouring matter was then withdrawn from these and other petals by macerating them for two days in cold methyl alcohol, the solution was poured off, evaporated to dryness, the residue taken up with warm water, and the solution after filtering tested as follows :-(I) One drop $\mathrm{HCl}$ or $\mathrm{H}^{3} \mathrm{PO}^{4}$, followed by several drops of ammonia; (2) solution of acetate of lead followed, or not, by acetic acid; (3) solution of acetate of magnesium. The results are tabulated as follows :-

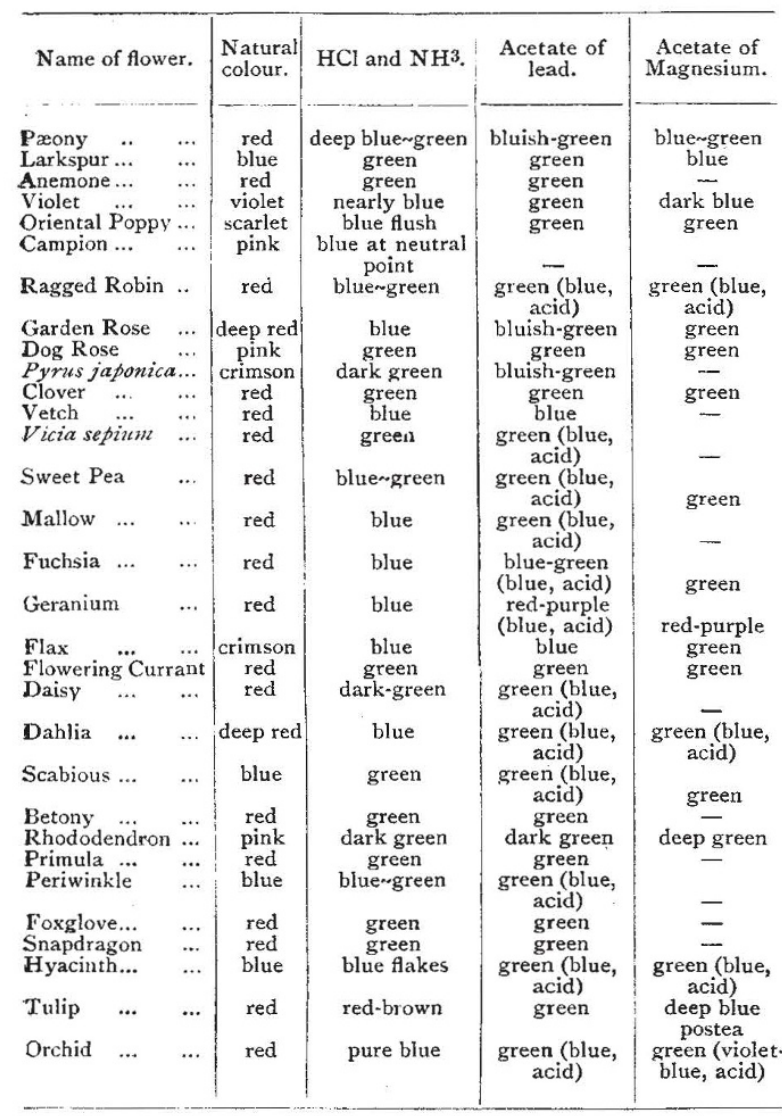

In a few cases the aqueous solution of the pigment, after acidification by $\mathrm{HCl}$, was shaken up with amyl alcohol, and after allowing to separate, the lower acid liquid was withdrawn, and tested with excess of ammonia and of acetate of lead. In this way, rhododendron, red daisy, red tulip, violet, foxglove, Vicia cracca, red poppy, gave a brilliant pure blue coloration; while, on the other hand, flowering currant and woundwort gave greens with ammonia, but blue precipitates with acetate of lead. In order, however, to purify the pigment still more thoroughly, its alcoholic or aqueous solution was shaken up at intervals for two days with well-washed hide-powder, and the latter, after filtering off the liquid, was well washed and extracted with very dilute $\mathrm{HCl}$. The bright red liquid thus obsained was treated successively with the aforementioned reagents. The result was extremely interesting; for while flowering currant and rhododendron gave greens, red tulip and purple orchis gave blues. In some cases the Wiesner's experiment was repeated, i.e. the fresh petals were warmed with dilute $\mathrm{HCl}$, and the acid quite washed out with water, and the now reddened organs placed into solutions of acetate of lead and acetate of zinc, when rhododendron, flowering currant, violet (in some cells), foxglove, Vicia cracca (in some cells), became green while, on the contrary, Geranium pratense, bugle, the rest of the cells of violet, and of Vicia cracca became blue. It was evident, therefore, that Wiesner's opinion that anthocyan is invariably blued by alkalis, \&c., and never greened, was not confirmed; inasmuch as at least three petals, when treated in the manner he prescribed, were distinctly greened, the presumption being that all yellow intermixture had been obviated.

The general conclusion which I think must needs be drawn from these my experiments is, that there are different stages in the development of the floral pigment. In the lower stages the natural colour is red, whatever the chromogen may be ; and so far Berzelius was right. In the higher stages, on the other hand, the natural colour of anthocyan is blue, or rather (at least with some chromogens) it becomes capable of forming blue compounds or lakes with alkalis and certain metallic salts. Moreover, as I have laboured to show elsewhere, chromogens exist which, except under very exceptional conditions and circumstances, are incapable of producing a blue pigment ; and these in all stages naturally develop into a red, the brilliancy of which, when contrasted with that of a blue accidentally obtained in an allied species (e.g. in flax), unequivocally attests its real, original, and proper character. P. Q. KEEGAN.

\section{The Colour of Flints.}

AN examination of the pebbles lying on the beach of the coast of the English Channel shows that while these are principally flints they vary considerably in colour.

The flints derived from the chalk cliffs surrounding this part or the coast, and from which the shingle is generally supposed to be derived, are, so far as my experience goes, invariably black, with a white coating on the exterior.

Only about one-third of the flints on the beaches of such localities as Eastbourne, Hastings, Brighton, Hythe, Folkestone, Dover, \&c., or in the large accumulations at Dungeness and at the Chesil Beach are apparently derived from the adjacent chalk cliffs, the remainder being different shades of brown, grey, white and red, the former being the most prevalent. In some cases the outside coating is of a different colour to the interior of the pebble. It follows, then, either that the flints from the chalk undergo some chemical action, either internally or externally, while exposed to the air and salt water of the beach, which changes their colour, or the majority of them must have been derived from inland gravels.

The first theory does not seem feasible, as flints are to be found in raised beaches and other positions, where they have been deposited for long periods, still retaining not only their interior black colour, but also the white coating on the outside.

If these various coloured beach flints are derived from inland gravel beds, they must have been deposited under different conditions from those which now prevail, as there is no action in operation on the south coast which can convey the flints from inland to the sea. The age of some of these shingle beds must, therefore, be much greater than has been generally supposed.

There are isolated pockets of gravel at the top of the chalk cliffs in some places, which fall on to the beach where the cliffs are eroded by the sea; but these are too few in number to account for immense deposits such as those at Dungeness, Pevensey and Chesil.

Failing to obtain any light on this subject from geologists to whom I have mentioned the matter, and whose opinions vary as to the changes flints undergo, I venture to appeal to NATURE for a solution.

Boston, Lincs., November 27.

\section{THE PROPOSED CHANGES IN THE MATHEMATICAL TRIPOS.}

THE Cambridge Board for Mathematics has presented to the Senate a report on the Mathematical Tripos. This report recommends certain changes in the regulations relating to that Tripos. The following note contains an abstract of the proposals made by the Board :-

The schedule of subjects for Part I. of the Tripos has been reduced by the entire omission of some subjects (calculus of variations, elliptic functions, Bessel's functions, hydrodynamics, sound). Other subjects have been limited in extent (e.g. rigid dynamics, electricity, optics, aštronomy and others). Care has been taken to specifically exclude parts of some subjects. The arrangement of papers is to be entirely changed and no papers are to be 
exclusively devoted to problems. At the present time particular methods are prohibited in answering the questions set in certain papers; such general restrictions of methods are no longer to be maintained. A special regulation provides that at least half the questions set throughout the examination shall be of an elementary character.

The Board also proposes to abandon the custom of publishing the list of successful candidates in order of merit, and to follow the method at present adopted in the Classical Tripos. There will be three classes (Wranglers, Senior and Junior Optimes), and each class will consist of three divisions, the names in each division being arranged in alphabetical order.

The proposed changes in Part I. have involved some corresponding changes in Part II. The class-list is to consist of three divisions only, the names in each division being arranged alphabetically; and it is to be possible for a candidate to obtain a place in the first division in two ways. He may do so (as at present) by showing special proficiency in one section of the schedule of subjects, together with general proficiency in one or more other sections ; or by showing general proficiency over a wider range of subjects.

The Board hopes that these changes will induce more men to take Part I. in their second year; it is at present possible to do so under a regulation which came into force in I 893, but very few have actually availed themselves of the rule (probably not I per cent. of the whole number of candidates since 1892). This is partly due to the fact that 90 per cent. of the candidates cannot cover the whole range of reading in two years, and partly to the natural desire of the more able men to appear in as high a place as possible in the list. By taking the Tripos in their second year, men who intend to study subjects such as physics or engineering will be able to gain a preliminary knowledge of mathematics, with indications as to how to extend their knowledge in any special branch which they may need in their future course. The second year Tripos will be of advantage also to the better mathematical men, who now spend half their third year in revision and in acquiring facility of solving artificial problems. Under the proposed regulations these men will have two years after Part I. (instead of one) in which to become acquainted with the ideas and methods of modern mathematics. This will be of special advantage to men who intend to devote themselves to mathematical research.

It is thought that the abolition of order of merit will assist the aims of the Board by making it possible for the papers to be easier, and by helping to remove artificial problems ; and also by inducing a greater number of men to take the Tripos in the second year of residence. It is further felt by many that the proposed Part I. is not of sufficient extent to even profess to classify the candidates in an exact final order of merit.

On November 23 the proposals of the Board were discussed by the Senate. As might be anticipated, the scheme was criticised at some length, and particularly the proposal to abolish the order of merit. The Board will now revise its suggestions in the light of the criticisms of the Senate, and the Senate will have to vote on the final recommendations of the Board.

It seems that the present Tripos must be modified in some way, as the number of candidates has been steadily falling off in recent years. Though once the largest Tripos in the University, the Mathematical Tripos is now smaller than both the Natural Science and the Classical Tripos. Taking an average of the candidates for the four years $1869-72$, we find that, of the resident undergraduates, one in eighteen passed the Mathematical Tripos; while for the five years $1895-99$, the average falls to one in thirty-five (of course, this relates to Part I. only).

No. I 570 , voL. 6 I]

\section{THE RESISTANCE OF THE AIR.}

THE mportance of determinations of the resistance of the air to moving bodies, in connection with the problem of aërial navigation and numerous other practical applications, has led the Société d'Encouragement pour l'Industrie Nationale to offer a prize for investigations of an essentially experimental nature dealing with the reactions on a surface moving through the air under varying conditions as to form and velocity. One series of experiments with this object has been undertaken by $M$. l'Abbé Le Dantec, and a second set by M. Canovetti. The following account of these researches is based on the papers communicated by their authors to the Bulletin of the Society, and the report on them by M. Barbet.

The method adopted by M. l'Abbé Le Dantec is very simple, and had been used in some previous experiments by him in 1893. It is based on the property that the motion of a falling body is at first accelerated, but the resistance of the air, increasing as the velocity increases, soon balances the weight of the body, and the body thus soon acquires its terminal velocity, and then moves uniformly. The resistance of the air at this velocity is exactly equal to the weight of the falling body.

In the present experiments the surface whose resistance is to be observed slides down a vertical wire, which acts as a guide without introducing perceptible friction. Its weight and area can be easily and accurately measured and Le Dantec has now devised an electric recording apparatus, which enables the time of fall to be estimated with equal precision. A band of paper is unrolled by clockwork action, and on this band an electric arrangement records the vibrations of a seconds pendulum. Furthermore, when the falling surface is released, a current is started whereby a toothed wheel is brought into contact with the paper band, and traces on it a dotted line. The surface at the end of its descent comes in contact with a buffer, the current is broken, and the cessation of the dotted line indicates the exact instant at which the surface reached the buffer. The operator can vary the height in such a way that the descent occupies one, two, three or more seconds, and by subtraction the distances traversed in each successive second are obtained.

The experiments were conducted in the chapel of the Conservatoire des Arts et Métiers, the nave of which is of considerable height, and their accuracy is verified by the perfect agreement of the results. Thus several experiments conducted for the purpose of determining the height through which a surface fell in a certain number of seconds agreed to within a centimetre. The chief conclusions are as follows :-

(I) Even feeble air currents such as are produced by persons moving about in the neighbourhood of the apparatus suffice to considerably modify the results, and it is important therefore that the experiments should be conducted in a closed building, which must, however, be sufficiently large for the walls not to materially affect the stream-lines of the air flowing past the moving surface.

(2) A square surface I metre square, moving with a velocity of I metre per second, experiences a resistance of $8 \mathrm{I}$ grammes.

(3) Experiments conducted with three different surfaces, each of I square metre in area, but of different forms, viz. circular, square, and of the form of an equilateral triangle, respectively, show that the resistance depends on the form of the surface, and the results accord with the hypothesis that the resistance of a surface of given area is proportional to the length of its contour. This property appears to be new.

(4) For velocities varying within certain limits, the law of proportionality of the resistance to the square of the velocity was verified.

The resistance of the air to a moving surface can also 